\title{
Tumor necrosis factor $\alpha$ modulates sodium- activated potassium channel SLICK in rat dorsal horn neurons via P38 MAPK activation pathway
}

This article was published in the following Dove Press journal:

Journal of Pain Research

25 May 2017

Number of times this article has been viewed

\section{Kun Wang' \\ Feng Wang' \\ Jun-Ping $\mathrm{Bao}^{2}$ \\ Zhi-Yang $X_{i e}$ \\ Lu Chen' \\ Bao-Yi Zhou' \\ Xin-Hui $X_{i e}{ }^{2}$ \\ Xiao-Tao $\mathrm{Wu}^{1,2}$}

'Medical School of Southeast University, ${ }^{2}$ Department of Orthopaedics, Zhongda Hospital, Southeast University, Nanjing, People's Republic of China
Correspondence: Xiao-Tao Wu Department of Orthopaedics, Zhongda Hospital, Southeast University, 87 Dingjia Bridge, Nanjing Shi, Jiangsu Sheng 210009 , People's Republic of China Email wuxiaotao@medmail.com.cn

\begin{abstract}
The dorsal horn (DH) of the spinal cord is the integrative center that processes and transmits pain sensation. Abnormal changes in ion channel expression can enhance the excitability of pain-related DH neurons. Sodium-activated potassium $\left(\mathrm{K}_{\mathrm{Na}}\right)$ channels are highly expressed particularly in the central nervous system; however, information about whether rat DH neurons express the SLICK channel protein is lacking, and the direct effects on SLICK in response to inflammation and the potential signaling pathway mediating such effects are yet to be elucidated. Here, using cultured DH neurons, we have shown that tumor necrosis factor- $\alpha$ inhibits the total outward potassium current $\mathrm{I}_{\mathrm{K}}$ and the $\mathrm{K}_{\mathrm{Na}}$ current predominantly as well as induces a progressive loss of firing accommodation. However, we found that this change in channel activity is offset by the p38 inhibitor SB202190, thereby suggesting the modulation of SLICK channel activity via the p38 MAPK pathway. Furthermore, we have demonstrated that the tumor necrosis factor- $\alpha$ modulation of $\mathrm{K}_{\mathrm{Na}}$ channels does not occur at the level of SLICK channel gating but arises from possible posttranslational modification.
\end{abstract}

Keywords: p38 MAPK, SLICK channel, neuropathic pain, dorsal horn, TNF- $\alpha$

\section{Introduction}

In recent years, sodium-activated potassium $\left(\mathrm{K}_{\mathrm{Na}}\right)$ channels have attracted considerable attention because of their role in maintaining the resting membrane potential and firing accommodation of the sensory neurons. ${ }^{1,2} \mathrm{~K}_{\mathrm{Na}}$ channels are encoded by the SLACK and SLICK genes. Although both channels may protect the neurons against noxious stimuli, ${ }^{3}$ SLICK may be more specialized for protective functions because of its higher sensitivity to intracellular $\mathrm{Cl}^{-}$and ATP. The dorsal horn (DH) of the spinal cord is the integrative center that processes and transmits pain sensation. ${ }^{4,5}$ Although $\mathrm{K}_{\mathrm{Na}}$ channels are particularly highly expressed in neurons, ${ }^{6}$ information about whether rat DH neurons express the SLICK channel protein was limited. In response to local inflammation, abnormal changes in ion channel expression can enhance the excitability of pain-related neurons $;^{7}$ however, direct empirical evidence for a $\mathrm{K}_{\mathrm{Na}}$ channel contribution to neuronal excitability has been lacking.

Tumor necrosis factor- $\alpha$ (TNF- $\alpha$ ), an important substance contributing to inflammation, is involved in the development of inflammatory pain, and the impairment of TNF signaling attenuates hypersensitivity in neuropathy. ${ }^{8-10}$ As previously reported, acute TNF- $\alpha$ stimulation at the dorsal root ganglion rapidly enhances TTX-R currents via the p38-dependent pathway, ${ }^{11}$ and TNF- $\alpha$-induced p38 MAPK activation regulates TRPA1 and TRPV4 activity in odontoblast-like cells. ${ }^{12}$ Although TNF- $\alpha$ has 
been shown to modulate potassium channel expression and mediate thermal hyperalgesia, ${ }^{13}$ its direct effects on SLICK and the potential signaling pathway mediating such effects have yet to be elucidated.

We hypothesized that p38 MAPK pathway activation plays an important role in the modulation of the SLICK channel and then enhances the excitability of DH neurons. In this study, we addressed two questions using cultures of DH neurons. First, we explored whether the DH neurons express the SLICK channel protein. Second, we investigated whether $\mathrm{p} 38 \mathrm{MAPK}$ pathways are involved in the mechanism by which TNF- $\alpha$ acts on the SLICK channel.

\section{Materials and methods}

\section{$\mathrm{DH}$ neuronal culture and treatments}

All surgical procedures and experiments were approved by the Ethical Committee of Southeast University and were in accordance with the Guidelines for the Care and Treatment of Laboratory Animals of the US National Institutes of Health. The DHs from Sprague-Dawley female rats (1 day of age, Qinglongshan, Nanjing, China) were extracted for all experiments. The DHs were dissected and enzymatically digested with $0.25 \%$ trypsin at $37^{\circ} \mathrm{C}$ for $50 \mathrm{~min}$. Mechanical dissociation and plating was then performed. The neurons were then placed in six-well plates with culture media (ThermoFisher, Shanghai, China) containing Neurobasal ${ }^{\circledR}$-A media, B27, $2 \mathrm{mM}$ l-glutamine, and the antibiotics penicillin and streptomycin. The cells were maintained in an incubator at $37^{\circ} \mathrm{C}$ and $5 \% \mathrm{CO}_{2}$ throughout the experiments. All subsequent experiments were followed by cell culture for 1 week, and the number of cells in each well of the six-well plate reached 60,000-75,000. For TNF- $\alpha$ treatment experiments, neurons were grown in six-well plates before treatment with $10 \mathrm{ng} / \mathrm{mL}$ TNF- $\alpha$ in the presence or absence of $10 \mu \mathrm{M}$ of $\mathrm{p} 38$ inhibitor SB202190 (Sigma, Gillingham, UK).

\section{DH neuron electrophysiology}

All data were acquired using Axon Clampex 10.6 (Molecular Devices). The high-pass filter setting was $2 \mathrm{kHz}$, and the sampling rate was $20 \mathrm{kHz}$. In the experimental process, we ensured that the quality of recording of DH neurons was determined by certain criteria, such as resting membrane potential, which is relatively stable; the series resistance was $<30 \mathrm{M} \Omega$ throughout the recording process and the degree of variation was $<20 \%$; the input resistance was $>400 \mathrm{M} \Omega$ and the degree of change was $<35 \%$. For current-clamp recordings, a Multiclamp $700 \mathrm{~B}$ (Molecular Devices) was used, and data were analog-digital converted using an Axon 1440A instrument. Glass electrodes were pulled using a horizontal pipette puller (Sutter Instrument Company, Novato, CA, USA) and fire polished to have a resistance of 6-10 $\mathrm{M} \Omega$. The repetitive discharge of each cell was measured by the injection of $2.5 \times$ threshold stimuli for $1000 \mathrm{~ms}$. The pipette solution contained the following (in $\mathrm{mM}$ ): $124 \mathrm{~K}$-gluconate, $2 \mathrm{MgCl}_{2}, 13.2 \mathrm{NaCl}, 1$ ethylene glycol-bis( $\beta$-aminoethyl ether)- $N, N, N^{\prime}, N^{\prime}$-tetraacetic acid [EGTA], 10 4-(2-hydroxyethyl)-1-piperazineethanesulfonic acid [HEPES], $4 \mathrm{Mg}$-ATP, and 0.3 Na-GTP at pH 7.2. The bath solution contained (in $\mathrm{mM}$ ) $140 \mathrm{NaCl}, 5.4 \mathrm{KCl}, 1 \mathrm{CaCl}_{2}$, $1 \mathrm{MgCl}_{2}, 15.6 \mathrm{HEPES}$, and 10 glucose at $\mathrm{pH} \mathrm{7.4.} \mathrm{For} \mathrm{the}$ voltage-clamp, pipettes were filled with solution containing (in $\mathrm{mM}$ ) $124 \mathrm{~K}$-gluconate, $2 \mathrm{MgCl}_{2}, 13.2 \mathrm{NaCl}, 1$ EGTA, 10 HEPES, 4 Mg-ATP, and 0.3 Na-GTP at pH 7.2. The bath solution for all cells contained (in $\mathrm{mM}$ ) $140 \mathrm{NaCl}, 5.4 \mathrm{KCl}$, $1 \mathrm{CaCl}_{2}, 1 \mathrm{MgCl}_{2}, 10 \mathrm{HEPES}$, and 10 glucose. When examining sodium-dependent potassium currents in isolation, $\mathrm{NaCl}$ was completely replaced with the impermeable cation $N$-methyl-d-glucamine (NMG-Cl) (Sigma). Identical bath and pipette solutions were used in both the voltage-clamp and current-clamp modes. In the voltage-clamp mode, the current was recorded at a holding potential of $-70 \mathrm{mV}$, with $2000 \mathrm{~ms}$ pulses ranging between -80 and $+50 \mathrm{mV}$.

\section{Real-time polymerase chain reaction}

The total RNA was extracted from the neuronal culture using the RNeasy Plus kit (Takara, RR047) according to the manufacturer's recommendations. Before reverse transcription, the total RNA was treated with RQ1 RNase-Free DNase (Promega) to remove genomic DNA. The cDNA was synthesized using an Invitrogen SuperScript ${ }^{\circledR}$ III kit (ThermoFisher). The primers used for $\mathrm{DH}$ neuronal culture were as follows: for GAPDH, GTTACCAGGGCTGCCTTCTC (forward) and GATGGTGATGGGTTTCCCGT (reverse), and for SLICK, GTGTGTGTGCTTGTGTTGCAG (forward) and GAGCACCTCCCATACGTCTTC (reverse). The slopes of the primer efficiency equation for the primer pairs used in this study were between -3.1 and -3.6 , giving reaction efficiencies between $90 \%$ and $110 \%$, which are typically acceptable for a quantitative PCR assay. The running protocol comprised 40 cycles consisting of $95^{\circ} \mathrm{C}$ for $15 \mathrm{~s}$ and $60^{\circ} \mathrm{C}$ for 1 min using an Applied Biosystems 7500 Fast Real-time PCR system. Each sample was measured in triplicate.

\section{Membrane protein biotinylation}

$\mathrm{DH}$ neurons in six-well plates were used $30 \mathrm{~min}$ following incubation with $10 \mathrm{ng} / \mathrm{mL}$ TNF- $\alpha / 10 \mu \mathrm{M}$ of p38 inhibitor SB202190. Then, $160 \mu \mathrm{L}$ of $10 \mathrm{mM}$ Sulfo-NHS-SS-Biotin 
(ThermoFisher) was added to each well, and the plates were incubated at room temperature for $45 \mathrm{~min}$. During this time, $100 \mu \mathrm{L}$ of Pierce Streptavidin Magnetic Beads (ThermoFisher) were washed with phosphate-buffered saline (PBS) $+0.1 \%$ Tween. After $45 \mathrm{~min}$, the cells were rinsed with PBS and lysed with a buffer containing PBS, $150 \mathrm{mM} \mathrm{NaCl}, 1 \%$ Nonidet P-40, and $0.1 \%$ sodium dodecyl sulfate, $\mathrm{pH} 8.0$, and a protease inhibitor cocktail. The samples were then incubated with $50 \mu \mathrm{L}$ of streptavidin beads (ThermoFisher) in a rotator overnight at $4^{\circ} \mathrm{C}$. On the following day, the samples were washed twice in PBS. After removing the supernatant, the beads were resuspended in Laemmli sample buffer (BioRad) and boiled for $5 \mathrm{~min}$. The samples were then loaded onto a Ready Gel, and Western blot analysis was performed to detect membrane SLICK.

\section{Cell viability assay}

The cell cytotoxicity of TNF- $\alpha$ and the effect of p38 inhibitor SB202190 on the viability of DH neurons were evaluated using a 3-(4,5-dimethylthiazol-2-yl)-2, 5-diphenyltetrazolium bromide (MTT) assay. Cells were incubated with $10 \mathrm{ng} / \mathrm{mL}$ TNF- $\alpha$ in the presence or absence of 10 $\mu \mathrm{M}$ SB202190. Afterward, $100 \mathrm{~mL}$ of a $0.5 \mathrm{mg} / \mathrm{mL}$ MTT solution (ThermoFisher) was added to the culture media. After incubation for $2 \mathrm{~h}$ at $37^{\circ} \mathrm{C}$ and the removal of culture medium, dimethyl sulfoxide was added to dissolve the formazan crystals. The absorbance at $570 \mathrm{~nm}$ was determined using an automatic microplate spectrophotometer. Data were analyzed using Prism GraphPad 6 software. Samples were measured in quintuplicate, and the experiment was performed in triplicate.

\section{Statistical analysis}

Statistical analyses were performed using SPSS statistical software (version 19.0, IBM). Data are presented as the mean \pm standard error. Unpaired $t$-test analyses were used to determine statistical significance $(p<0.05)$.

\section{Results}

Voltage-clamp whole-cell recordings were performed using these $\mathrm{DH}$ neurons. The average current density at 50 $\mathrm{mV}$ was $320.96 \pm 34.94 \mathrm{pA} / \mathrm{pF}$ (Figure $1 \mathrm{~A}, \mathrm{n}=5$ ). When the sodium in the bath and pipette solution was replaced with the impermeant cation NMG, the $\mathrm{I}_{\mathrm{K}}$ of the DH neurons was greatly reduced, and the average current density at $50 \mathrm{mV}$ was $197.07 \pm 20.98 \mathrm{pA} / \mathrm{pF}$ (Figure $1 \mathrm{~A}, \mathrm{n}=5$ ), $\sim 40 \%$ of its control value (Figure $1 \mathrm{~B}, p<0.05$, unpaired $t$-tests). Using whole-cell current-clamp recording on cultured $\mathrm{DH}$ neurons, we typically saw firing of $<2$ action potentials in 5 neurons, in response to $2.5 \times$ the stimulus threshold before TNF- $\alpha$ stimulation (Figure 2A). After the application of $10 \mathrm{ng} / \mathrm{mL}$ TNF- $\alpha$, a progressive loss of firing accommodation was observed in 5 neurons (Figure 2B), and after $10 \mathrm{~min}$, no firing accommodation was observed in 5 neurons (Figure $2 \mathrm{C})$. However, in $\mathrm{DH}$ neurons incubated with $10 \mu \mathrm{M}$ of p38 inhibitor SB202190 for $30 \mathrm{~min}$ before the short TNF- $\alpha$ treatment, no loss of firing accommodation was detected (Figure 2D, $\mathrm{n}=5$ ).

Using whole-cell voltage-clamp recording, we assayed the effect of p38 MAPK activation on the $I_{K}$ in the DH neurons in the presence and absence of $\mathrm{Na}^{+}$in the bath. In external solutions without $\mathrm{Na}^{+}(0 \mathrm{mM})$, the average current density at $5 \mathrm{mV}$ was $152.23 \pm 21.44 \mathrm{pA} / \mathrm{pF}$, and $10 \mathrm{~min}$
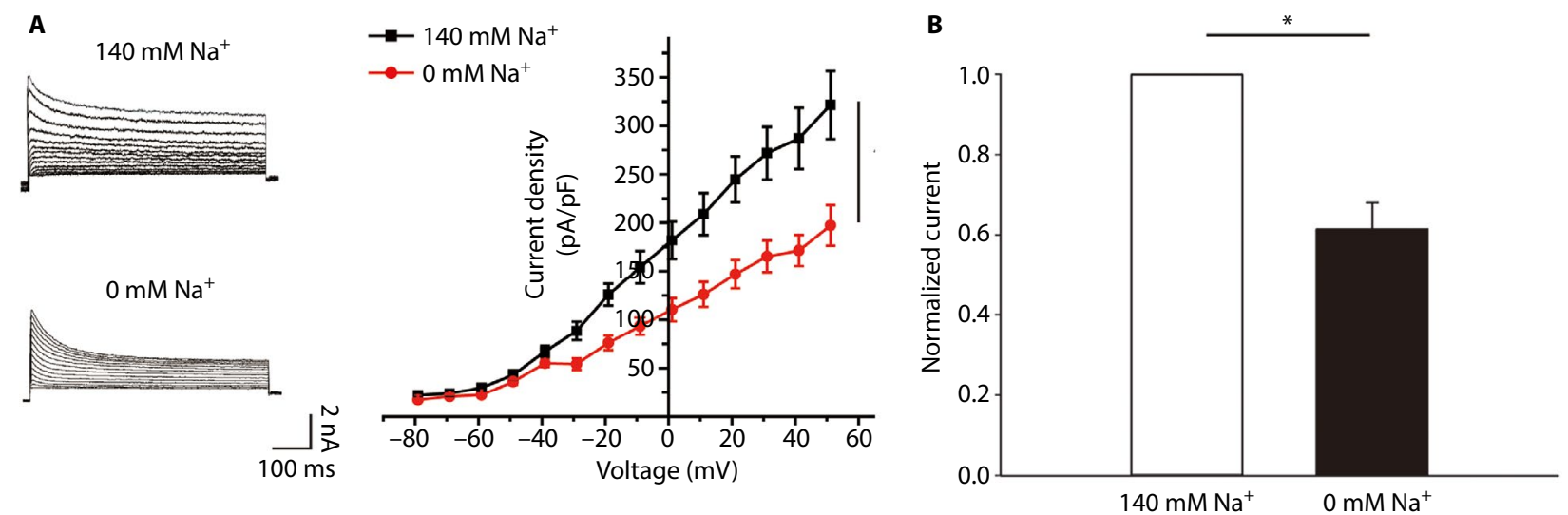

Figure I Voltage-clamp whole-cell recordings were conducted in $\mathrm{DH}$ neurons.

Notes: (A) Current was recorded at a holding potential of $-70 \mathrm{mV}$, with $2000 \mathrm{~ms}$ pulses between -80 and $+50 \mathrm{mV}$. Neuron was initially recorded in $140 \mathrm{mM}$ external $\mathrm{Na}^{+}$ and then perfused with a solution in which $\mathrm{NaCl}$ was completely replaced with the impermeable cation $\mathrm{N}$-methyl-d-glucamine (NMG-Cl). (B) Removal of extracellular $\mathrm{Na}{ }^{+}$ reduces $\mathrm{I}_{\mathrm{K}}$ in $\mathrm{DH}$ neurons. $* P<0.05$.

Abbreviation: $\mathrm{DH}$, dorsal horn. 

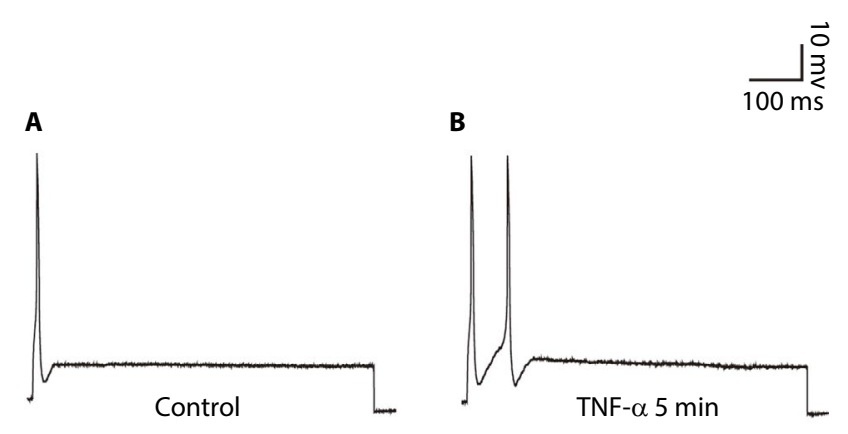

c

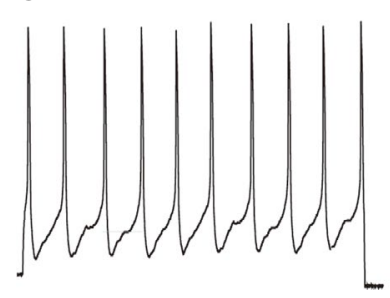

TNF- $\alpha 10 \mathrm{~min}$
D

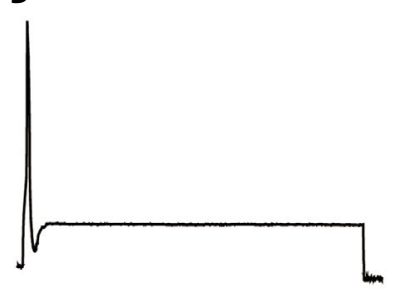

TNF- $\alpha 10 \mathrm{~min} / \mathrm{SB} 202190$

Figure 2 SB202 190 restores the firing accommodation of DH neurons. Notes: (A) Representative action potential recorded in untreated neurons. (B) 5 min application of $10 \mathrm{ng} / \mathrm{mL}$ TNF- $\alpha$, neurons exhibited a progressive loss of firing accommodation. (C) $10 \mathrm{~min}$ application of $10 \mathrm{ng} / \mathrm{mL}$ TNF- $\alpha$, neurons showed completed loss of firing accommodation. (D) $\mathrm{DH}$ neurons were incubated with $10 \mu M$ of p38 inhibitor SB202190 for 30 min before TNF- $\alpha$ treatment; no loss of firing accommodation was detected. Using whole-cell current-clamp on cultured $\mathrm{DH}$ neurons, stimulation was $2.5 \times$ threshold for $1000 \mathrm{~ms}$.

Abbreviation: $\mathrm{DH}$, dorsal horn.

after the application of $10 \mathrm{ng} / \mathrm{mL}$ TNF- $\alpha$, we observed a small but significant decrease in $\mathrm{I}_{\mathrm{K}}$. The average current density at $50 \mathrm{mV}$ was $140.46 \pm 20.19 \mathrm{pA} / \mathrm{pF}$; only an $8 \%$ decrease in $\mathrm{I}_{\mathrm{K}}$ (Figure 3B, n=5) was observed when normalized to the control (Figure 3F, $p<0.05$, unpaired $t$-tests). In parallel experiments in which neurons were bathed in an extracellular bath containing physiological levels of $\mathrm{Na}^{+}(140 \mathrm{mM})$, the average current density at $50 \mathrm{mV}$ was $250.19 \pm 34.85 \mathrm{pA} / \mathrm{pF}$, and the application of $10 \mathrm{ng} / \mathrm{mL}$ TNF- $\alpha$ caused a much greater decrease in $\mathrm{I}_{\mathrm{K}}$. The average current density at $50 \mathrm{mV}$ was $166.92 \pm 20.92 \mathrm{pA} / \mathrm{pF}$ (Figure $3 \mathrm{~A}, \mathrm{n}=5$ ). After the application of TNF- $\alpha$, there was a $34 \%$ decrease in $\mathrm{I}_{\mathrm{K}}$ when normalized to the control (Figure $3 \mathrm{E}, p<0.01$, unpaired $t$-tests), a significantly larger percentage decrease than in $\mathrm{Na}^{+}$-free conditions $(p<0.05)$. These results strongly suggest that under physiological recording conditions, p38 MAPK strongly inhibits $\mathrm{I}_{\mathrm{K}}$, particularly the $\mathrm{K}_{\mathrm{Na}}$ component of $\mathrm{I}_{\mathrm{K}}$. The loss of firing accommodation caused by TNF- $\alpha$ could, therefore, likely be attributed to the inhibition of $\mathrm{K}_{\mathrm{Na}}$. To test whether reduced p38 MAPK activity would produce the opposite effect, DH neurons were incubated with $10 \mu \mathrm{M}$ of p38 inhibitor SB202190 for 30 min before TNF- $\alpha$ treatment, which produced a nonsignificant increase in total $\mathrm{I}_{\mathrm{K}}$ (Figure 3C). This effect was not seen upon replacing $\mathrm{Na}^{+}$

with NMG; instead, we observed a small decrease in the total outward current (Figure 3D), implying the presence of other unidentified potassium current(s) that are likely subject to $\mathrm{p} 38$ MAPK modulation.

We determined whether TNF- $\alpha$ can decrease the expression of the channel protein to understand how it could decrease the current densities of SLICK channels. A surfaceexpression biotinylation assay showed that TNF- $\alpha$ decreased SLICK protein expression significantly (Figure $4 \mathrm{~A}, \mathrm{n}=5$, $p<0.05$, unpaired $t$-tests). Meanwhile, we conducted parallel studies in which TNF- $\alpha$ was inhibited by pretreating neurons with $10 \mu \mathrm{M}$ of SB202190 for $30 \mathrm{~min}$ followed by TNF- $\alpha$ treatment. In this case, surface SLICK channel expression was comparable to unstimulated neurons (Figure 4B). Furthermore, reverse transcription polymerase chain reaction analysis was performed on DH neurons incubated with TNF- $\alpha$ to determine whether the TNF- $\alpha$-induced downregulation of SLICK proteins in DH neurons resulted from a reduction in transcription. We found no significant difference in SLICK mRNA expression compared with unstimulated neurons (Figure 4C). Our results showed that TNF- $\alpha$ directly decreased SLICK channel activity through possible posttranslational modification (PTM). We confirmed using the MTT assay that SB202190 in combination with TNF- $\alpha$ exerted no effect on the viability of DH neurons (Figure 5).

\section{Discussion}

In this study, we provided the first evidence that the SLICK $\mathrm{K}_{\mathrm{Na}}$ channel is expressed in rat DH neurons and that TNF- $\alpha$ can reduce the expression of SLICK $\mathrm{K}_{\mathrm{Na}}$ channels at the protein level in DH neurons. Moreover, we showed that the inflammatory cytokine TNF- $\alpha$ decreases SLICK $\mathrm{K}_{\mathrm{Na}}$ expression at the membrane through a 38 MAPK-dependent pathway. Our study suggested that $\mathrm{K}^{+}$exit decreased in $\mathrm{DH}$ neurons after TNF- $\alpha$ or $\mathrm{p} 38$ activation and reducing the number of $\mathrm{K}_{\mathrm{Na}}$ channels at the plasma membrane will result in loss of the firing accommodation.

Accumulating evidence has demonstrated that TNF- $\alpha$ is an effective activator of neuropathic pain. ${ }^{14}$ The MAPK family of kinases plays an important role in mammalian cell signaling. One kinase of the MAPK, p38, was reported to be increased in animal models of neuropathic pain. ${ }^{15} \mathrm{TNF}-\alpha$ activates multiple signaling pathways, including the p38 MAPK pathway, ${ }^{16}$ which is recognized as an important regulator of inflammatory pain, ${ }^{17}$ although TNF- $\alpha$ can also activate ERK or c-JUN of MAPK. ${ }^{18}$ Our results established the p38 MAPK-mediated downregulation of SLICK $\mathrm{K}_{\mathrm{Na}}$ expression in DH neurons and demonstrated, for the first time, a novel mechanism by which 
A

$140 \mathrm{mM} \mathrm{Na}^{+}$
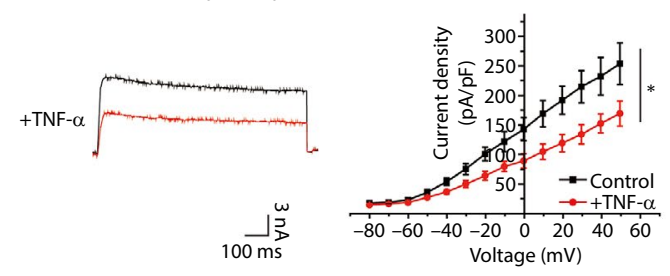

c
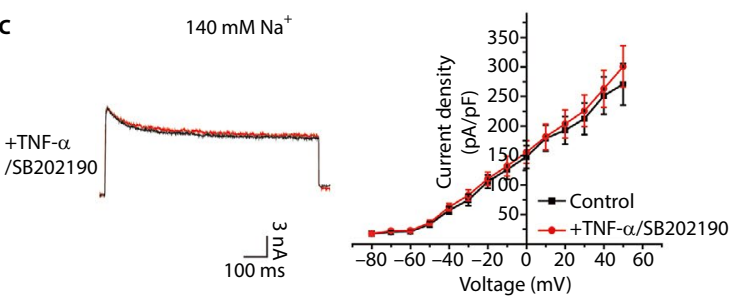

E

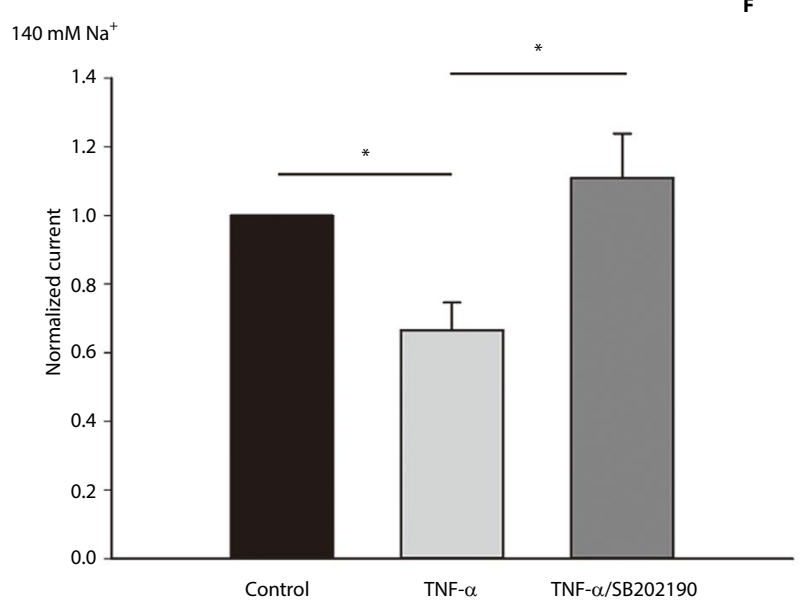

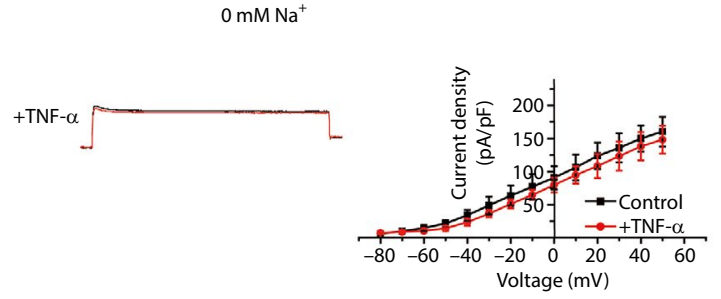

D
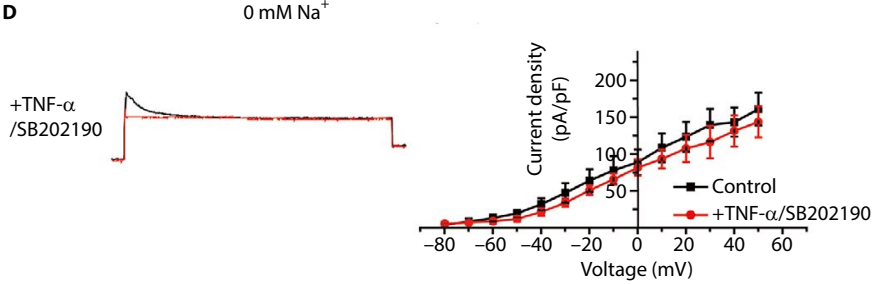

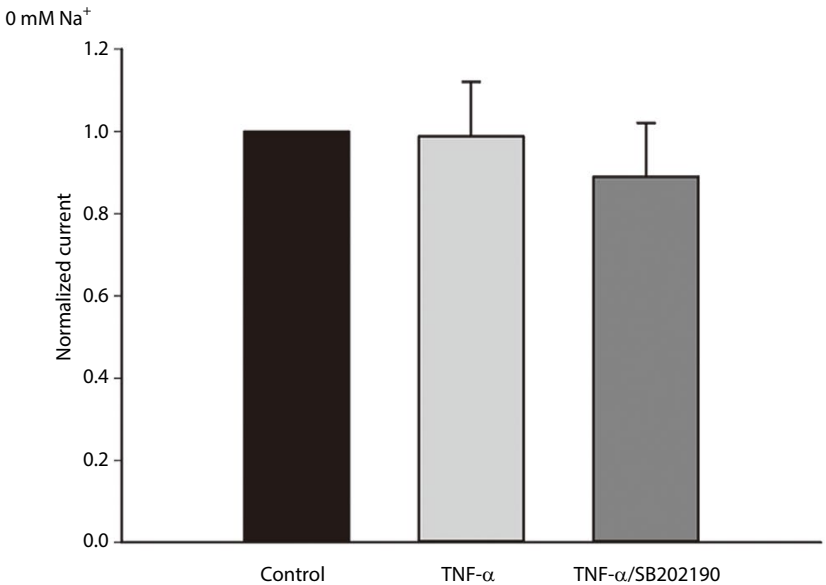

Figure 3 The $K_{\mathrm{Na}}$ current is significantly decreased in DH neurons treated with TNF- $\alpha$ via p38 MAPK.

Notes: (A, B) Left, Representative traces of $\mathrm{I}_{\mathrm{K}}$ recorded before and after application of $10 \mathrm{ng} / \mathrm{mL} \mathrm{TNF}-\alpha$ in 140 and $0 \mathrm{mM} \mathrm{Na}^{+}$external solution; Right, Current-voltage relationships before and after TNF- $\alpha$ treatment. (C, D) Left, Representative traces of $I_{K}$ recorded before and after application of $10 \mu M$ of $p 38$ inhibitor SB202I 90 for 30 min and then $10 \mathrm{~min}$ TNF- $\alpha$ treatment in $140 \mathrm{mM}$ and $0 \mathrm{mM} \mathrm{Na}{ }^{+}$external solution; Right, Current-voltage relationships before and after SB202। 90 and then TNF- $\alpha$ treatment. (E, F) Peak current after $10 \mathrm{ng} / \mathrm{mL}$ TNF- $\alpha$ and TNF- $\alpha$ combined SB202190 addition at $50 \mathrm{mV}$ normalized to control for both 140 and $0 \mathrm{mM} \mathrm{Na-containing} \mathrm{extracellular} \mathrm{solution.} * P<0.05$. Abbreviations: $\mathrm{DH}$, dorsal horn; TNF- $\alpha$, tumor necrosis factor-alpha.

p38 MAPK could contribute to decreasing SLICK $\mathrm{K}_{\mathrm{Na}}$ channel responses via nontranscriptional mechanisms.

In this study, three types of firing patterns were identified in response to depolarizing current injections, namely, single-spiking, tonic-firing, and delayed-firing. We clamped only the single-spiking neurons and found that TNF- $\alpha$ can cause loss of firing accommodation, but this effect can be counteracted by $\mathrm{p} 38 \mathrm{MAPK}$ inhibitors. The findings were that in our culture preparation, the electrophysiological properties of DH neurons were similar to the properties of $\mathrm{DH}$ neurons recorded in young spinal cord slices. ${ }^{19} \mathrm{~K}_{\mathrm{Na}}$ channel expression decreases in vivo under pathological conditions accompanied by thermal hyperalgesia. ${ }^{20}$ Knockdown of $\mathrm{K}_{\mathrm{Na}}$ SLACK channels also decreases the firing accommodation in DRG neurons. ${ }^{21}$ We found that the SLICK channel mRNA remained unchanged, but the protein declined after exposure to TNF- $\alpha$. Our results showed that these changes might be induced through the PTM of ion channels. Channel phosphorylation is the most common PTM. The action of kinases on SLICK channels is to decrease the current amplitude. ${ }^{22}$ Ubiquitylation is also a well-known PTM that negatively regulates the cell surface expression of many different plasma membrane proteins. $^{23}$

We hypothesized that the mechanism underlying the neuropathic pain involved alterations in the SLICK channel, which could contribute to the abnormal excitability of DH neurons. These observations could explain our previous study, which showed that the TNF- $\alpha$ blood protein levels in the sciatica group were significantly higher than in healthy subjects. ${ }^{24}$ However, this sensitization could not be concluded to be a result of the direct phosphorylation or ubiquitylation of SLICK channels by p38 MAPK. In addition, to date, the 


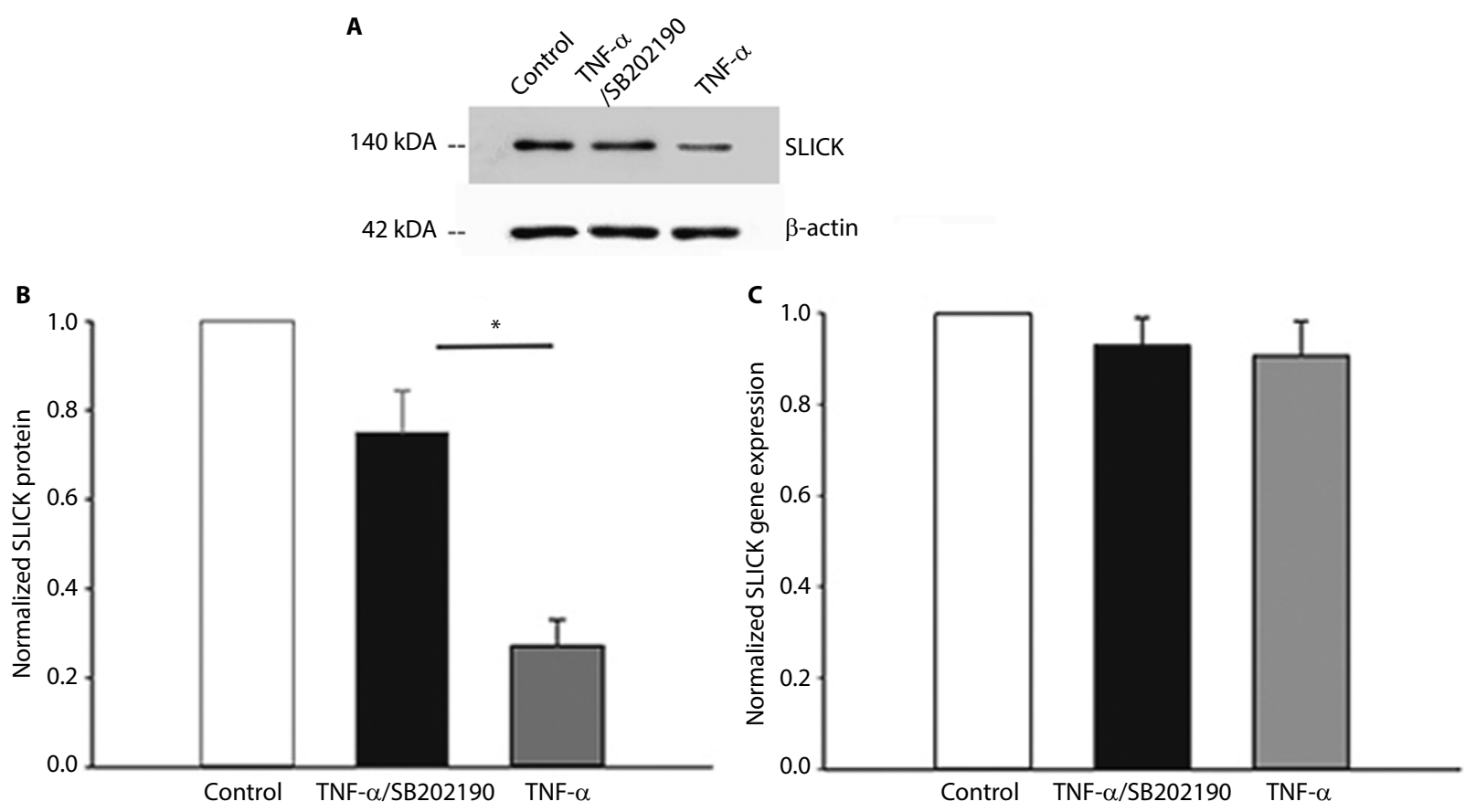

Figure 4 TNF- $\alpha$ decreases membrane expression of SLICK channels via p38 MAPK through possible posttranslational modification in DH neurons.

Notes: (A) Representative blot of membrane SLICK biotinylation assay. Membrane biotinylation and precipitation by streptavidin followed by Western analysis using a SLICK-specific antibody were performed on untreated neurons, neurons treated with $10 \mathrm{ng} / \mathrm{mL}$ TNF- $\alpha$ for 10 min, or neurons pretreated with $10 \mu M$ of 338 inhibitor SB202190 for $30 \mathrm{~min}$ followed by $10 \mathrm{ng} / \mathrm{mL}$ TNF- $\alpha$ for $10 \mathrm{~min}$. (B) Densitometric analysis of SLICK membrane expression when normalized to $\beta$-actin. (C) Normalized SLICK gene expression levels. $* P<0.05$.

Abbreviations: DH, dorsal horn; TNF- $\alpha$, tumor necrosis factor-alpha.

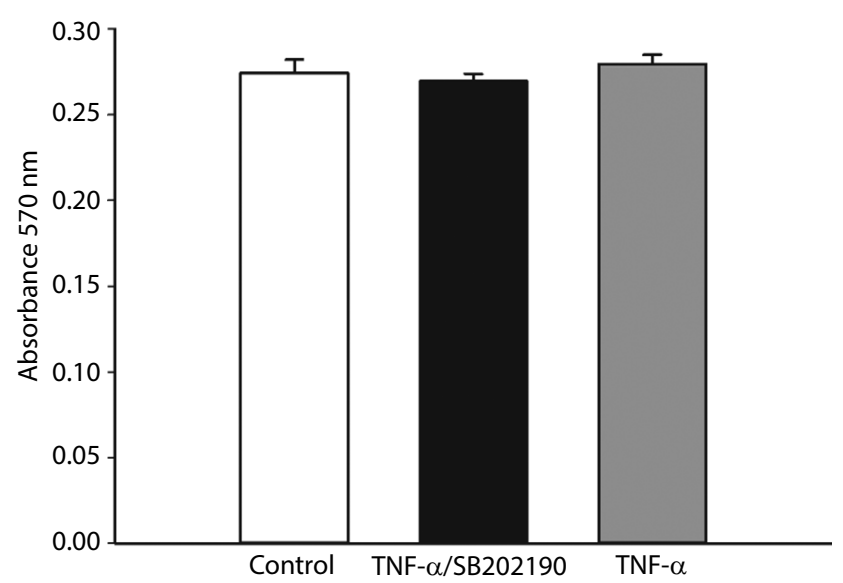

Figure 5 The cell cytotoxicity of TNF- $\alpha$ and the effect of p38 inhibitor SB202190 on the viability of DH neuron were evaluated using MTT assay.

Notes: MTT assay that SB202190 in combination with TNF- $\alpha$ exerted no effect on the viability of $\mathrm{DH}$ neurons.

Abbreviations: DH, dorsal horn; TNF- $\alpha$, tumor necrosis factor-alpha.

onset of expression and detailed mapping of SLICK channel distribution in the $\mathrm{DH}$ during embryonic and postnatal development are missing, and therefore the effects of TNF- $\alpha$ may also change during this developmental period. Further work is needed to investigate this possibility.

\section{Acknowledgments}

The work was supported by the National Natural Science Foundation of China (Nos. 81572170 and 81572109). The authors thank Zi-Kai Zhou (Southeast University) for expert technical assistance. They also thank American Journal Expert for language polishing.

\section{Disclosure}

The authors report no conflicts of interest in this work.

\section{References}

1. Tomasello DL, Gancarz-Kausch AM, Dietz DM, Bhattacharjee A. Transcriptional regulation of the sodium-activated potassium channel SLICK (KCNT2) promoter by nuclear factor-kappaB. J B Chem. 2015;290(30):18575-18583.

2. Cervantes B, Vega R, Limon A, Soto E. Identity, expression and functional role of the sodium-activated potassium current in vestibular ganglion afferent neurons. Neuroscience. 2013;240:163-175.

3. Bhattacharjee A, Joiner WJ, Wu M Yang Y, Sigworth FJ, Kaczmarek LK. Slick (Slo2.1), a rapidly-gating sodium-activated potassium channel inhibited by ATP. J Neurosci. 2003;27(37):11681-11691.

4. Willis Jr WD, Coggeshall RE. Sensory Mechanisms of the Spinal Cord. 3rd edition. Vol 1. New York, NY: Kluwer Academic, Plenum Publishers; 2004.

5. Basbaum AI, Bautista DM, Scherrer G, Julius D. Cellular and molecular mechanisms of pain. Cell. 2009;139(2):267-284.

6. Bhattacharjee A, Kaczmarek LK. For K+ channels, Na+ is the new Ca2+. Trends Neurosci. 2005;28(8):422-428.

7. Waxman SG, Zamponi GW. Regulating excitability of peripheral afferents: emerging ion channel targets. Nat Neurosci. 2014;17(2):153-163.

8. Ellis A, Bennett D. Neuroinflammation and the generation of neuropathic pain. Br J Anaesth. 2013;111(1):26-37.

9. Zhang Q, Yu J, Wang J, et al. The red nucleus TNF- $\alpha$ participates in the initiation and maintenance of neuropathic pain through different signaling pathways. Neurochem Res. 2015;40(7):1360-1371. 
10. Clark AK, Old EA, Malcangio M. Neuropathic pain and cytokines: current perspectives. J Pain Res. 2013;6:803-814.

11. Jin X. Acute $\mathrm{p} 38$-mediated modulation of tetrodotoxin-resistant sodium channels in mouse sensory neurons by tumor necrosis factor-alpha. J Neurosci. 2006;26(1):246-255.

12. El Karim I, McCrudden MT, Linden GJ, et al. TNF-alpha-induced p38MAPK activation regulates TRPA1 and TRPV4 activity in odontoblast-like cells. Am J Pathol. 2015;185(11):2994-3002.

13. El Hachmane M-F, Rees KA, Veale EL, Sumbayev VV, Mathie A. Enhancement of TWIK-related Acid-sensitive potassium channel 3 (TASK3) two-pore domain potassium channel activity by tumor necrosis factor $\alpha . J$ Biol Chem. 2014;289(3):1388-1401.

14. Andrade P, Hoogland G, Del Rosario JS, Steinbusch HW, VisserVandewalle V, Daemen MA. Tumor necrosis factor- $\alpha$ inhibitors alleviation of experimentally induced neuropathic pain is associated with modulation of TNF receptor expression. J Neurosci Res. 2014;92(11): 1490-1498.

15. Berta T, Qadri YJ, Chen G, Ji RR. Microglial signaling in chronic pain with a special focus on caspase 6,p38 MAP kinase, and sex dependence. $J$ Dent Res. 2016;95(10):1124-1131.

16. Wu H. Assembly of post-receptor signaling complexes for the tumor necrosis factor receptor superfamily. Adv Protein Chem. 2004;68: $225-279$.
17. Schäfers M, Svensson CI, Sommer C, Sorkin LS. Tumor necrosis factor- $\alpha$ induces mechanical allodynia after spinal nerve ligation by activation of p38 MAPK in primary sensory neurons. J Neurosci. 2003; 23(7):2517-2521.

18. Ji RR, Gereau RWt, Malcangio M, Strichartz GR. MAP kinase and pain. Brain Res Rev. 2009;60(1):135-148.

19. Ruscheweyh R, Sandkühler J. Lamina-specific membrane and discharge properties of rat spinal dorsal horn neuronesin vitro. J Physiol. 2002;541(1):231-244.

20. Huang F, Wang X, Ostertag EM, et al. TMEM16C facilitates $\mathrm{Na}(+)-$ activated $\mathrm{K}+$ currents in rat sensory neurons and regulates pain processing. Nat Neurosci. 2013;16(9):1284-1290.

21. Nuwer MO, Picchione KE, Bhattacharjee A. PKA-induced internalization of slack $\mathrm{KNa}$ channels produces dorsal root ganglion neuron hyperexcitability. J Neurosci. 2010;30(42):14165-14172.

22. Santi CM, Ferreira G, Yang B, et al. Opposite regulation of Slick and Slack K+ channels by neuromodulators. J Neurosci. 2006;26(19):5059-5068.

23. Laedermann CJ, Abriel H, Decosterd I. Post-translational modifications of voltage-gated sodium channels in chronic pain syndromes. Front Pharmacol. 2015;6:263.

24. Wang K, Bao JP, Yang S, et al. A cohort study comparing the serum levels of pro-or anti-inflammatory cytokines in patients with lumbar radicular pain and healthy subjects. Eur Spine J. 2016;25(5):1428-1434.
Journal of Pain Research

\section{Publish your work in this journal}

The Journal of Pain Research is an international, peer reviewed, open access, online journal that welcomes laboratory and clinical findings in the fields of pain research and the prevention and management of pain. Original research, reviews, symposium reports, hypothesis formation and commentaries are all considered for publication.

\section{Dovepress}

The manuscript management system is completely online and includes a very quick and fair peer-review system, which is all easy to use. Visit http://www.dovepress.com/testimonials.php to read real quotes from published authors. 